Check for updates

Cite this: RSC Adv., 2018, 8, 37828

Received 11th August 2018

Accepted 22nd October 2018

DOI: $10.1039 / c 8 r a 06754 f$

rsc.li/rsc-advances

\section{Sensitive fluorescent assay for copper(II) determination in aqueous solution using quercetin-cyclodextrin inclusion $\uparrow$}

\author{
Shilong Yang, (iD ab Weina Jiang, ${ }^{\text {bc }}$ Ying Tang, ${ }^{\text {ad }}$ Li Xu, iD *be Buhong Gao ${ }^{a}$ \\ and Haijun $\mathrm{Xu}^{\star c}$
}

Environmentally friendly probe materials for detecting copper ions were studied in this research. Fluorescent emission of quercetin (Q) was observed in the buffer solution $(\mathrm{pH}=7.40$ ), and (2hydroxypropyl)- $\beta$-cyclodextrin (CD) could enhance the fluorescence intensity of $Q$. The UV/Vis spectrum showed that the Q-CD system was formed. After adding copper ions into the Q-CD system, the fluorescent emission intensity of Q-CD system generated quenching, and other metal ions could not bring change, which meant the Q-CD system showed good selectivity to copper ions. The fluorescence titration spectra showed that the concentration of copper ions was inversely proportional to fluorescence intensity, and gave a good linear change in fluorescence emission intensity in response to the concentration of copper ions ranging from $5.0 \times 10^{-8}$ to $8.3 \times 10^{-6} \mathrm{~mol} \mathrm{~L}^{-1}$. The calibration curve of the relationship between the intensity and copper ions concentration was $y=-9.24 x+844.51\left(R^{2}=\right.$ 0.997). The detection limit of copper ions was measured to be $2.3 \times 10^{-8} \mathrm{~mol} \mathrm{~L}^{-1}$. The probable mechanism was studied by UV/Vis spectrum and Job's plot method. The results indicated that Q-CD$\mathrm{Cu}($ II) complex was formed and intramolecular charge transfer (ICT) took place. At last, the probe was successfully applied for determination of copper ions in water bodies, vegetables and fruits with good recovery. The study showed that Q-CD system could detect copper ions as a fluorescent probe with high selectivity, sensitivity and larger linearity range.

\section{Introduction}

As one of essential trace elements in living organisms, copper ions participate in many biological processes, such as various redox processes, enzyme functions, and so on. ${ }^{1}$ However, excessive amounts of copper ions in bodies could cause a series of diseases, such as Menkes syndrome, Wilson's disease, familial amyotrophic lateral sclerosis, prion diseases and Alzheimer's disease..$^{2-4}$ With the development of the industrialization, more and more copper ions from electrical and electronics industries, mining industry, electroplating industry, etc. are being released into environment, which directly influences humans' health. Thus, it is very important to detect copper ions in the environment. Up to now, numerous analytical methods

${ }^{a}$ Advanced Analysis and Testing Center, Nanjing Forestry University, Nanjing, 210037, China

${ }^{b}$ Co-Innovation Center for Sustainable Forestry in Southern China, Nanjing Forestry University, 210037, China.E-mail: xuliqby@njfu.edu.cn

${ }^{c}$ College of Chemical Engineering, Nanjing Forestry University, 210037, China

${ }^{d}$ College of Forestry, Nanjing Forestry University, Nanjing, 210037, China

${ }^{e}$ College of Science, Nanjing Forestry University, Nanjing, 210037, China

$\dagger$ Electronic supplementary information (ESI) available. See DOI: $10.1039 / \mathrm{c} 8 \mathrm{ra} 06754 \mathrm{f}$ have been studied to detect copper ions, including atomic absorption spectroscopy (AAS), inductively coupled plasma mass spectroscopy (ICP-MS), inductively coupled plasma atomic emission spectroscopy (ICP-AES), electrochemical assays, colorimetric methods and fluorescent probes. ${ }^{5-10}$ Methods such as AAS, ICP-MS and ICP-AES can detect copper ion with high sensitivity and selectivity but with requirements of large instruments. Compared with other methods, fluorescent probes possess many more advantages, for instance high sensitivity, real-time detection, low cost, and simplicity for implementation. As a consequence, much more attention has been given to fluorescent probes. In recent years, significant emphasis has been placed on the development of new, highly selective fluorescent sensors for copper ions. Thousands of fluorescent sensors for copper ions have been reported. ${ }^{11-15}$ But the majority of the fluorescent probes are synthesized by organic reaction with some toxic reagents and cumbersome process, only few fluorescent probes come directly from natural products. It is reported that quercetin, biochanin A and isorhamnetin could act as fluorescent probes for detecting copper ions with good selectivity and high sensitivity. ${ }^{16-18}$ However, the fluorescence intensity of flavonoids is low, which would limit the linearity range for detecting copper ions. In recent years, more and more methods have been developed to improve the 
fluorescence intensity of fluorescent probes. For example, nucleic acids could enhance the fluorescence intensity of quercetin, ${ }^{19}$ and silver nanoparticles could help to enhance the fluorescence intensity of the quercetin and nucleic acids system..$^{20}$ It is reported that the fluorescence intensity of berberine in aqueous medium was greatly enhanced by (2hydroxypropyl)- $\beta$-cyclodextrin (CD). ${ }^{21}$ In addition, quantum dots, metal ions, surfactants etc. were also used to enhance the fluorescence intensity of some compounds. ${ }^{22-25}$ Among these, water-soluble CD possesses good biological compatibility and lower toxicity, so CD has good application prospect.

Quercetin ( $\mathbf{Q}$, Scheme 1) is a natural product widely present in most plants and belongs to flavonoid with good biological activity. Our previous research showed $\mathbf{Q}$ could act as fluorescent probes for detecting copper ions, but the fluorescence intensity of $\mathbf{Q}$ was low, and the ferrous ions could affect the recognition process of copper ions. ${ }^{16}$ While in this study, it was amazedly found that $\mathbf{C D}$ could greatly enhance the fluorescence intensity of $\mathbf{Q}$ in the $\mathrm{CH}_{3} \mathrm{OH}-\mathrm{PBS}$ buffer solution $(1: 99, \mathrm{v} / \mathrm{v}, \mathrm{pH}$ $=7.40$ ), and the $\mathbf{Q}-\mathbf{C D}$ system could act as a fluorescent probe for detecting copper ions with high selectivity, sensitivity and larger linearity range. The Q-CD system was obtained by mixing two solutions directly and interacted with each other by supramolecular action without chemical reaction. At last, the content of copper ions in water bodies, vegetables and fruits was measured by the Q-CD system.

\section{Results and discussion}

\subsection{The influence of $C D$ on fluorescent intensity of $Q$}

To study the influence of $\mathbf{C D}$ content on the fluorescence emission intensity of $\mathbf{Q}$, various contents of $\mathbf{C D}$ were added, and the fluorescence emission spectra of $\mathbf{Q}$ were obtained (Fig. 1). In the Fig. 1, it clearly found that $\mathbf{Q}$ had a fluorescence emission peak at $543 \mathrm{~nm}$, and CD didn't show any fluorescence emission peak from $500 \mathrm{~nm}$ to $700 \mathrm{~nm}$. When adding the $\mathbf{C D}$ into Q, the fluorescence emission intensity of $\mathbf{Q}$ became stronger with the increasing of $\mathbf{C D}$, at the same time fluorescence emission peak at $543 \mathrm{~nm}$ was shifted to $553 \mathrm{~nm}$. When the mass ratio of $\mathbf{Q}$ to CD was $1: 900$, the increasing trend became flat. Thus the mass ratio 1 : 900 was decided to be one of experimental conditions in this study.

The fluorescence emission intensity, maximum emission peak and stability of $\mathbf{Q}$ had changed when adding $\mathbf{C D}$, which meant the interaction between $\mathbf{Q}$ and $\mathbf{C D}$ had taken place. To understand the interaction, UV/Vis spectra, ${ }^{1} \mathrm{H}$ NMR spectra

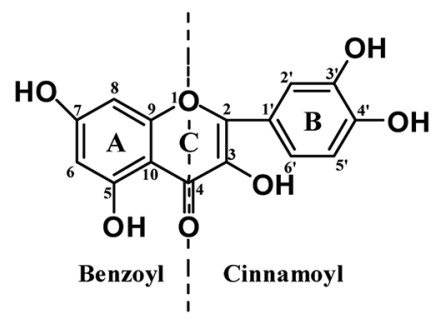

Scheme 1 Structure of the quercetin.

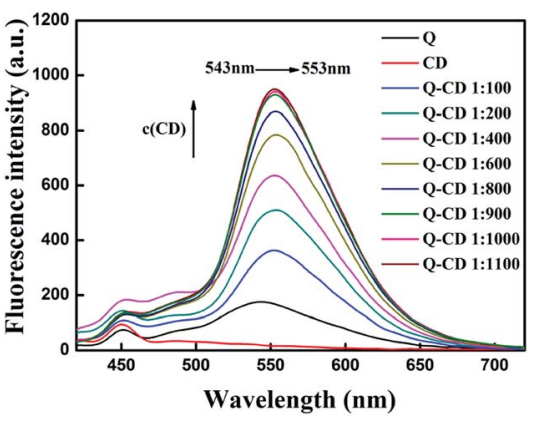

Fig. 1 The effect of $\mathrm{CD}$ on the fluorescence intensity of $\mathrm{Q}$ in $\mathrm{CH}_{3} \mathrm{OH}-$ PBS buffer solution ([Q] $=1.0 \times 10^{-5} \mathrm{~mol} \mathrm{~L}^{-1}$ ).

and FT-IR spectra had been studied. In the UV/Vis spectra (Fig. 2), $\mathbf{Q}$ had two major absorption bands at $375 \mathrm{~nm}$ (band I) and $260 \mathrm{~nm}$ (band II), which were characteristic absorptions of flavonoids related to B-ring cinnamoyl system and A-ring benzoyl system, respectively. ${ }^{26} \mathbf{C D}$ had no obvious absorption peak from $220 \mathrm{~nm}$ to $600 \mathrm{~nm}$. When adding CD into Q, the absorbance of $\mathbf{Q}$ at $327 \mathrm{~nm}$ increased, the absorbance of $\mathbf{Q}$ at $375 \mathrm{~nm}$ decreased and was shifted to $379 \mathrm{~nm}$. These phenomena indicated that $\mathbf{Q}$ had interacted with $\mathbf{C D}$, and the $\mathbf{Q}$ CD system formed.

The ${ }^{1} \mathrm{H}$ NMR spectra of $\mathbf{C D}, \mathbf{Q}$ and $\mathbf{Q}-\mathbf{C D}$ system were showed as Fig. S1-S3. $\dagger$ The chemical shifts of Q-CD system had obvious change comparing with that of $\mathbf{Q}$ (shown in Table S1 $\dagger$ ). The chemical shifts of 7-OH, 3-OH, 4'-OH and $3^{\prime}-\mathrm{OH}$ almost disappeared in Q-CD system, at the same time, the chemical shifts of $5-\mathrm{OH}$ and $2^{\prime}-\mathrm{H}$ and $6^{\prime}-\mathrm{H}$ shifted to high field, the chemical shifts of $5^{\prime}-\mathrm{H}, 8-\mathrm{H}$ and 6-H shifted to low field. In Q-CD system, $\mathbf{Q}$ entered into CD's hydrophobic cavity which interdicted hydrogen-bond interaction between $\mathbf{Q}$ and DMSO. So, strong and sharp peaks of four hydroxyl groups in $\mathbf{Q}$ were almost gone in Q-CD system. Meanwhile, the chemical shifts of other H of $\mathbf{Q}$ also changed slightly under influence by $\mathbf{C D}$. The peak of 5-OH in Q-CD system could still be seen clear although it became weak, which might due to intramolecular hydrogen bonds. These results suggested that Q-CD system is inclusion complex.

The FT-IR spectrum of $\mathbf{C D}, \mathbf{Q}$ and $\mathbf{Q}-\mathbf{C D}$ system were showed in Fig. S4 and S5. $\dagger$ The band at $1667 \mathrm{~cm}^{-1}$ for $\mathbf{Q}$, due to carbonyl, disappeared in $\mathbf{Q}-\mathbf{C D}$ system, which implied that $\mathbf{Q}$ had got into CD's cavity.

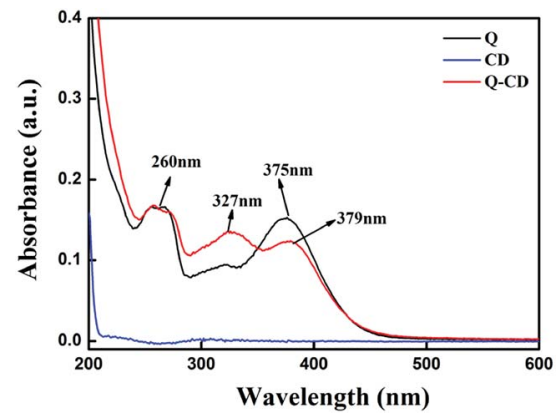

Fig. 2 The effect of $C D$ on the UV/Vis absorption spectra of $Q$ in $\mathrm{CH}_{3} \mathrm{OH}-\mathrm{PBS}$ buffer solution ([Q] $=1.0 \times 10^{-5} \mathrm{~mol} \mathrm{~L}^{-1}$ ). 
The further experiments showed that the fluorescence emission intensity of Q-CD system showed almost no change within $12 \mathrm{~h}$, however that of $\mathbf{Q}$ changed obviously within $5 \mathrm{~h}$ (Fig. S6†), which indicated the stability of Q-CD system was higher than that of $\mathbf{Q}$. The better stability of Q-CD system would improve the experimental accuracy and reproducibility. CD is cyclic oligosaccharides with cavity structures, and $\mathbf{Q}$ would be limited in the cavity and interacted with $\mathbf{C D}$ by weak hydrogen bond and hydrophobic interaction. ${ }^{27-29}$ The molecular mobility and collisions of $\mathbf{Q}$ molecules were limited by the formation of inclusion complexes, which prevented the transmission of energy among $\mathbf{Q}$ molecules. As a result, the fluorescence emission intensity and stability were increased as adding $\mathbf{C D} .^{30}$ The most probable structures of Q-CD system was showed as Scheme 2.

\subsection{Selectivity of the detection system}

To investigate the selectivity of Q-CD system on different metal ions, each kind of metal ions $\left(\mathrm{Li}^{+}, \mathrm{Na}^{+}, \mathrm{K}^{+}, \mathrm{Mg}^{2+}, \mathrm{Ca}^{2+}, \mathrm{Cr}^{3+}\right.$, $\mathrm{Mn}^{2+}, \mathrm{Fe}^{2+}, \mathrm{Fe}^{3+}, \mathrm{Co}^{2+}, \mathrm{Ni}^{2+}, \mathrm{Cu}^{2+}, \mathrm{Zn}^{2+}, \mathrm{Pb}^{2+}, \mathrm{Cd}^{2+}, \mathrm{La}^{3+}, \mathrm{Ce}^{3+}$, $\left.\mathrm{Nd}^{3+}, \mathrm{Eu}^{3+}, \mathrm{Gd}^{3+}, \mathrm{Dy}^{3+}\right)$ was added into Q-CD system, respectively. The results were showed in the Fig. 3. When adding $\mathrm{Cu}^{2+}$ into Q-CD system, the fluorescence emission intensity decreased sharply. None of the other metal ions generated obvious influence on fluorescence signals, even at higher concentrations. $\mathrm{Fe}^{2+}$ induced interference for $\mathbf{Q}$ as probe to recognize $\mathrm{Cu}^{2+}$, while for the $\mathbf{Q}-\mathbf{C D}$ system, $\mathrm{Fe}^{2+}$ did not affect the sensing process (Fig. S7†), which indicated Q-CD system could recognize $\mathrm{Cu}^{2+}$ with better selectivity than $\mathbf{Q}$.

To study the influence of the other metal ions on the recognition of $\mathbf{Q}-\mathbf{C D}$ system to $\mathrm{Cu}^{2+}$, each of the other metal ions was added into Q-CD-Cu(II) system, respectively. The results were showed in the Fig. 4. The fluorescence emission intensity of Q-CD-Cu(II) system varied only slightly when adding the other metal ions, which suggested that the recognition process of $\mathrm{Cu}^{2+}$ was hardly influenced by other metal ions. That is, Q-CD system had high selectivity on sensing $\mathrm{Cu}^{2+}$.

\subsection{Sensitivity of the detection system}

To obtain quantitative relation of Q-CD system on sensing $\mathrm{Cu}^{2+}$, the fluorescence titration experiments were carried out (Fig. 5).

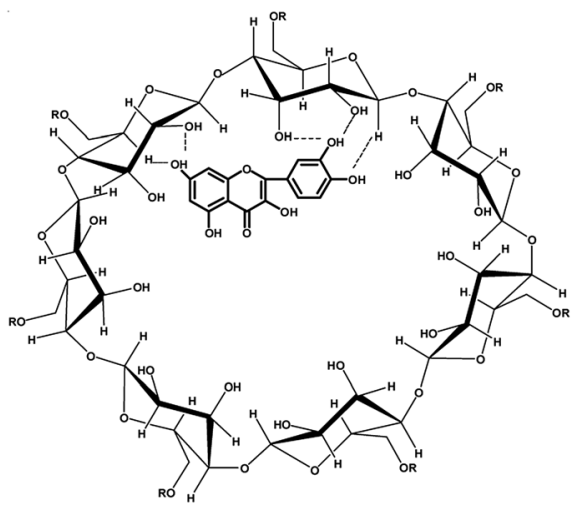

Scheme 2 The most probable structure of Q-CD system.

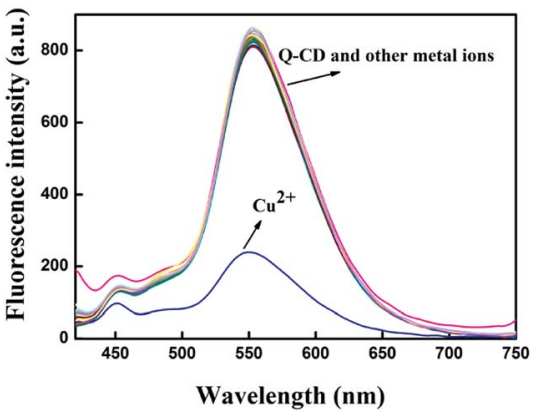

Fig. 3 The influence of different cations on fluorescent intensity of $Q$ $\mathrm{CD}$ system in $\mathrm{CH}_{3} \mathrm{OH}-\mathrm{PBS}$ buffer solution $\left([\mathrm{Q}]=1.0 \times 10^{-5} \mathrm{~mol} \mathrm{~L}^{-1}\right.$, $\left[\mathrm{Cu}^{2+}\right]=1.0 \times 10^{-5} \mathrm{~mol} \mathrm{~L}^{-1},[\mathrm{CD}]=2.72 \mathrm{~g} \mathrm{~L}^{-1}$, the concentration of other transition metal cations and rare earth cations was $2.0 \times$ $10^{-5} \mathrm{~mol} \mathrm{~L}^{-1}$, the concentration of alkali metal cations and alkali earth metal cations was $5.0 \times 10^{-5} \mathrm{~mol} \mathrm{~L}^{-1}$ ).

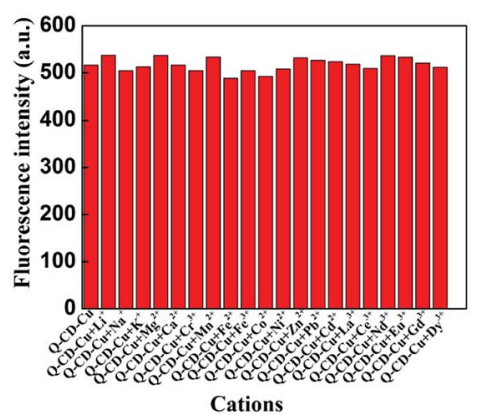

Fig. 4 The influence of other metal ions on fluorescent intensity of $Q$ $\mathrm{CD}-\mathrm{Cu}(\mathrm{II})$ system ([Q] $=1.0 \times 10^{-5} \mathrm{~mol} \mathrm{~L}{ }^{-1},\left[\mathrm{Cu}^{2+}\right]=2.5 \times$ $10^{-6} \mathrm{~mol} \mathrm{~L}^{-1}$, the concentration of other transition metal cations and rare earth cations was $1.0 \times 10^{-5} \mathrm{~mol} \mathrm{~L}^{-1}$, the concentration of alkali metal cations and alkali earth metal cations was $5.0 \times 10^{-5} \mathrm{~mol} \mathrm{~L}^{-1}$ ).

It was obviously to find that the fluorescence emission intensity at $553 \mathrm{~nm}$ gradually decreased with the $\mathrm{Cu}^{2+}$ concentration increased. The fluorescence emission intensity was inversely proportional to $\mathrm{Cu}^{2+}$ concentration ranging from $5.0 \times 10^{-8}$ to $8.3 \times 10^{-6} \mathrm{~mol} \mathrm{~L}^{-1}$. The calibration curve of the quantitative relationship between the fluorescence emission intensity and

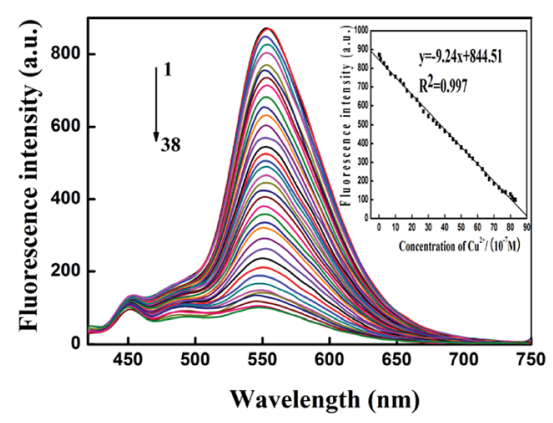

Fig. 5 Fluorescence titration of Q-CD system and standard curve of fluorescence titration spectra with varying concentrations of $\mathrm{Cu}^{2+}$ in $\mathrm{CH}_{3} \mathrm{OH}-\mathrm{PBS}$ buffer solution ([Q] $=1 \times 10^{-5} \mathrm{~mol} \mathrm{~L}^{-1}$, from 1 to 38 , $\left[\mathrm{Cu}^{2+}\right]=(0,0.5,1.0,3.0,5.0,7.0,10.0,13.0,15.0,17.0,20.0,23.0,25.0$, $27.0,30.0,33.0,35.0,37.0,40.0,43.0,45.0,47.0,50.0,53.0,55.0,57.0$, $60.0,63.0,65.0,67.0,70.0,73.0,75.0,77.0,80.0,81.0,82.0,83.0) \times$ $10^{-7} \mathrm{~mol} \mathrm{~L}^{-1}$, respectively.) 
$\mathrm{Cu}^{2+}$ concentration was $y=-9.24 x+844.51\left(R^{2}=0.997\right)$. The detection limit of $\mathrm{Cu}^{2+}$ was $2.3 \times 10^{-8} \mathrm{~mol} \mathrm{~L}^{-1}$, which was lower than that of many other sensors for $\mathrm{Cu}^{2+}$, and the linearity range was larger (Table S2 $\dagger$ ). The reproducibility of the probe was good (Table S3 $†$ ). These results indicated Q-CD system had good sensitivity on $\mathrm{Cu}^{2+}$ and the standard curve with good linearity could be used to quantify.

\subsection{Proposed mechanism}

During detecting $\mathrm{Cu}^{2+}$ with $\mathbf{Q}$-CD system as fluorescent probe, fluorescence quenching occurred, which meant $\mathrm{Cu}^{2+}$ interacted with Q-CD system. Combining with previous research results, ${ }^{4,17}$ Q-CD-Cu(II) complex may be formed in the buffer solution. In order to study the structure of Q-CD-Cu(II) complex, UV-visible spectra, FT-IR spectra and Job's plots experiments were carried out.

As mentioned, the UV-visible spectrum of $\mathbf{C D}$ had no obvious absorption peak from $220 \mathrm{~nm}$ to $600 \mathrm{~nm}$. When adding $\mathrm{Cu}^{2+}$ into $\mathbf{C D}$, the UV-visible spectrum had no obvious change (Fig. S8 $†$ ). The UV-visible spectra of Q-CD system were shown in Fig. 6. The UV-visible spectrum of Q-CD system in buffer solution showed three major absorption bands at $379 \mathrm{~nm}$ (band I), $327 \mathrm{~nm}$ and $260 \mathrm{~nm}$. In comparison with Q-CD system absorption spectrum, when $\mathrm{Cu}^{2+}$ added, band I was shifted to $430 \mathrm{~nm}$, which was a characteristic of the formation of the QCD-Cu(II) complex. At the same time, the colour of the solution was changed into dark yellow during the coordination reaction (Fig. S9†). Such bathochromic shift can be explained by the extension of the conjugated system. While adding the other ions, the UV-visible absorption spectra of Q-CD system had no obvious change (Fig. S10 $\dagger$ ), the UV-visible spectra were similar, just like the red line in Fig. 6. The FT-IR spectra of Q-CD and QCD-Cu(II) were studied in Fig. S11 and S12. $\uparrow$ The main change in the spectra was the shift of $\mathrm{C}=\mathrm{O}$. The $\mathrm{C}=\mathrm{O}$ stretching mode of Q-CD system was $1654 \mathrm{~cm}^{-1}$, when adding $\mathrm{Cu}^{2+}$ into the Q-CD system, the $\nu_{\mathrm{C}=\mathrm{O}}$ was shifted to $1639 \mathrm{~cm}^{-1}$, which was a characteristic of coordination of $\mathrm{C}=\mathrm{O}$ and $\mathrm{Cu}^{2+}$, which suggested the $\mathbf{Q}-\mathbf{C D}-\mathbf{C u}(\mathrm{II})$ complex formed.

In order to detect the stoichiometric ratio of $\mathrm{Cu}^{2+}$ and $\mathbf{Q}$ in $\mathbf{Q}-$ CD-Cu(II) complex, Job's plots experiments were done. In order to avoid the influence of absorbance band at $379 \mathrm{~nm}$ and $430 \mathrm{~nm}$, the absorption band at $458 \mathrm{~nm}$ was chosen for Job's plots curves. The absorbance plots at $458 \mathrm{~nm}$ against the molar

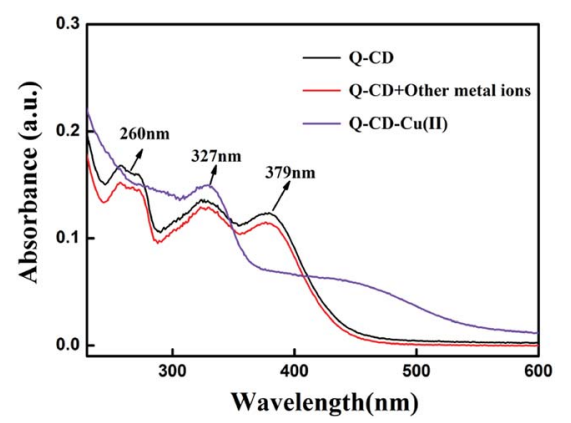

Fig. 6 The influence of different cations on UV/Vis absorption spectra of $\mathrm{Q}-\mathrm{CD}$ system in $\mathrm{CH}_{3} \mathrm{OH}-\mathrm{PBS}$ buffer solution. fraction of $\mathbf{Q}(\chi)$ have maximum absorbance at $\chi=0.52$, confirming that the stoichiometric ratio for the complex of $\mathbf{Q}$ and $\mathrm{Cu}^{2+}$ was $1: 1$ (Fig. 7). The stability constant $(K)$ of the complex was calculated to be $1.05 \times 10^{7}$, which meant that the stability of Q-CD-Cu(II) complex was very high.

The UV-visible spectra showed that absorption band at $379 \mathrm{~nm}$ was shifted to $430 \mathrm{~nm}$ when the Q-CD-Cu(II) complex formed, which indicated the B-ring cinnamoyl system participated in the reaction with $\mathrm{Cu}^{2+}$. As the 3-hydroxy group had a more acidic proton, therefore the 3-hydroxy and 4-carbonyl groups were the first sites to be involved in the complexation process. On the basis of the reports ${ }^{32-34}$ and our previous researches, the most probable coordination site was between 3hydroxyl and 4-carbonyl of $\mathbf{Q}$, and the most probable structure of Q-CD-Cu(II) complex was showed as Scheme 3.

When $\mathrm{Cu}^{2+}$ meet Q-CD system, Q-CD-Cu(II) complex formed, and intramolecular charge transfer (ICT) occurs due to the extension of the conjugated system, subsequently, fluorescence quenching of Q-CD system took place (Scheme 4), which was similar to biochanin A. ${ }^{17}$

\subsection{Detecting $\mathrm{Cu}^{2+}$ in real samples}

To demonstrate the feasibility of the probe Q-CD system, we applied this method for detecting $\mathrm{Cu}^{2+}$ in vegetables, fruits, rivers and lakes. The results were obtained by Q-CD system probe and ICP-AES or AAS, respectively (Table 1 and 2). Compared with ICP-AES/AAS method, the results obtained by

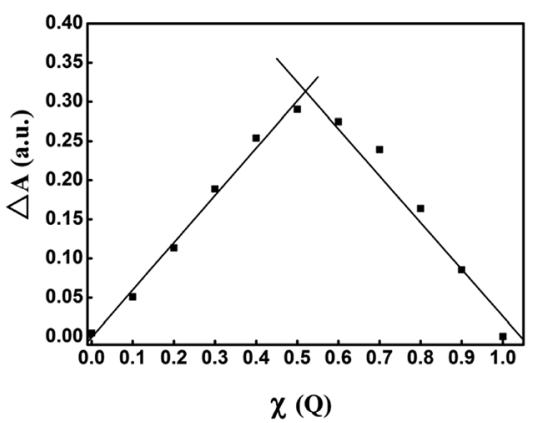

Fig. 7 Job's plots of Q-CD-Cu(॥) complex in $\mathrm{CH}_{3} \mathrm{OH}-\mathrm{PBS}$ buffer solution.

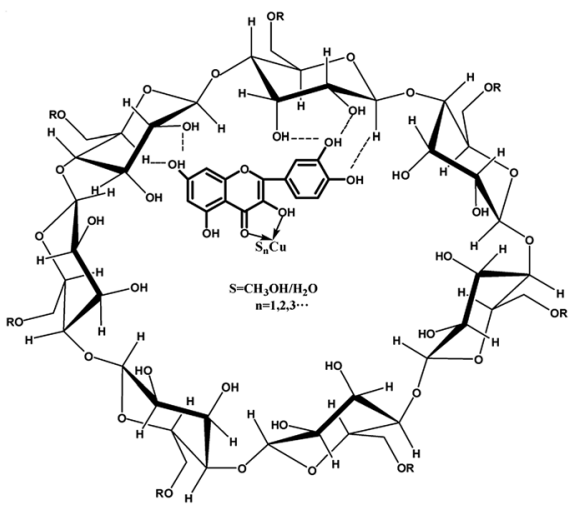

Scheme 3 The most probable structure of Q-CD-Cu(II) complex. 


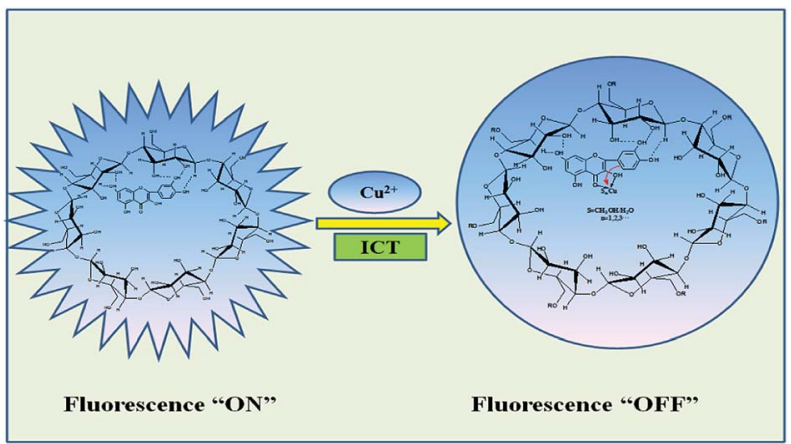

Scheme 4 Mechanism for Q-CD system sensing copper ions.

the Q-CD system probe were also accurate and had good recovery, which proved this method could be used to detect $\mathrm{Cu}^{2+}$ quantitatively.

\section{Experimental}

\subsection{Chemicals and instruments}

All reagents and solvents were of analytical reagent grade and used without further purification unless otherwise noted. $\mathrm{MeOH}$ was chromatographic grade and produced by TEDIA (America). CD was purchased from Sinopharm Chemical Reagent Co., Ltd. (China). Q was extracted from Ginkgo biloba leaves which were collected from Nanjing Forestry University. Phosphate Buffer Solution (PBS) was purchased from Beijing Solarbio Science \& Technology Co., Ltd. All solutions were freshly prepared using ultrapure water before experiments and used immediately.

PerkinElmer LS55 spectrophotometer was employed to record the fluorescence spectra, and excitation wavelength was $390 \mathrm{~nm}$ for all measurements. UV-visible absorption spectra were performed on a PerkinElmer Lambda 950 spectrophotometer. FT-IR spectra were obtained on a Bruker VERTEX 80V. The purified $\mathbf{Q}$ was obtained from Waters 1525 HPLC equipped with 2489 UV/Visible Detector, Fraction Collector III and 2707 Autosampler. ${ }^{1} \mathrm{H}$ NMR spectra were performed on a Bruker AVANCE III HD 600/500 spectrometer and ESI-MS on a Thermo

Table 1 Determination of $\mathrm{Cu}^{2+}$ in vegetables and fruits

\begin{tabular}{llllr}
\hline Samples & Found $(\mathrm{ppm})$ & AAS $(\mathrm{ppm})$ & RSD $(\%)$ & Recovery $(\%)$ \\
\hline Potato & $0.726 \pm 0.015$ & 0.781 & 2.00 & 92.99 \\
Tomato & $0.525 \pm 0.006$ & 0.493 & 1.22 & 106.57 \\
Watermelon & $0.222 \pm 0.003$ & 0.223 & 1.38 & 99.49 \\
Apple & $0.673 \pm 0.007$ & 0.651 & 1.18 & 103.45
\end{tabular}

Table 2 Determination of $\mathrm{Cu}^{2+}$ in rivers and lakes

\begin{tabular}{|c|c|c|c|c|}
\hline Samples & Found $/ c \times 10^{8} / \mathrm{mol} \mathrm{L}^{-1}$ & ICP-AES $/ c \times 10^{8} / \mathrm{mol} \mathrm{L}^{-1}$ & $\mathrm{RSD} / \%$ & Recovery $/ \%$ \\
\hline The Shuhe river & $6.479 \pm 0.083$ & 6.398 & 1.28 & 101.27 \\
\hline The Xiuzhen river & $3.432 \pm 0.058$ & 3.512 & 1.70 & 97.71 \\
\hline The Baima Lake & $7.237 \pm 0.074$ & 6.928 & 1.02 & 104.46 \\
\hline
\end{tabular}

Fisher Scientific LTQ Orbitrap XL ${ }^{\mathrm{TM}}$. As a comparison, LEEMAN LABS INC. Prodigy ICP-AES or AA900T AAS were also employed to measure the amount of copper ions in samples.

\subsection{Extraction and purification}

Q was extracted from Ginkgo biloba leaves according to the reported method with some modification. ${ }^{18,35}$ The chromatogram was shown in Fig. S13. $\dagger$ The fraction at 9.5 min was collected and dried under reduced pressure. Then the yellow product was obtained after washing with water. $\mathrm{Mp}>280{ }^{\circ} \mathrm{C}$. ESI-MS (Fig. S14†) $\mathrm{m} / z, 301.04[\mathrm{M}-\mathrm{H}]^{-} .{ }^{1} \mathrm{H}$ NMR (DMSO-d 6 600 MHz, Fig. S15†): 12.52 (s, 1H, 5-OH), 10.79 (s, 1H, 7-OH), 9.60 (s, $1 \mathrm{H}, 3-\mathrm{OH}), 9.36\left(\mathrm{~s}, 1 \mathrm{H}, 4^{\prime}-\mathrm{OH}\right), 9.32\left(\mathrm{~s}, 1 \mathrm{H}, 3^{\prime}-\mathrm{OH}\right), 7.72(\mathrm{~d}, J=$ $\left.2.16 \mathrm{~Hz}, 1 \mathrm{H}, 2^{\prime}-\mathrm{H}\right), 7.58\left(\mathrm{~d} \times \mathrm{d}, J_{1}=10.68 \mathrm{~Hz}, J_{2}=2.16 \mathrm{~Hz}, 1 \mathrm{H}\right.$, $\left.6^{\prime}-\mathrm{H}\right), 6.93\left(\mathrm{~d}, J=8.46 \mathrm{~Hz}, 1 \mathrm{H}, 5^{\prime}-\mathrm{H}\right), 6.44\left(\mathrm{~d}, J=1.98 \mathrm{~Hz}, 1 \mathrm{H}, 8^{-}\right.$ $\mathrm{H}), 6.22(\mathrm{~d}, J=2.04 \mathrm{~Hz}, 1 \mathrm{H}, 6-\mathrm{H})$.

\subsection{Preparation of the stock solutions}

$0.1 \mathrm{mmol}$ of each acetate/nitrate salts of different metal ions $\left(\mathrm{Li}^{+}, \mathrm{Na}^{+}, \mathrm{K}^{+}, \mathrm{Mg}^{2+}, \mathrm{Ca}^{2+}, \mathrm{Cr}^{3+}, \mathrm{Mn}^{2+}, \mathrm{Fe}^{2+}, \mathrm{Fe}^{3+}, \mathrm{Co}^{2+}, \mathrm{Ni}^{2+}, \mathrm{Cu}^{2+}\right.$, $\left.\mathrm{Zn}^{2+}, \mathrm{Pb}^{2+}, \mathrm{Cd}^{2+}, \mathrm{La}^{3+}, \mathrm{Ce}^{3+}, \mathrm{Nd}^{3+}, \mathrm{Eu}^{3+}, \mathrm{Gd}^{3+}, \mathrm{Dy}^{3+}\right)$ was dissolved in ultrapure water $(10 \mathrm{~mL})$ to afford $1 \times 10^{-2} \mathrm{~mol} \mathrm{~L}^{-1}$ aqueous solution. The stock solutions were diluted to desired concentrations when needed.

Q-CD system was prepared by mixing the solution of $\mathbf{Q}$ in $\mathrm{MeOH}$ and the solution of CD in PBS $(\mathrm{pH}=7.40)$ with volume ratio 1 : 99. In the $\mathbf{Q}-\mathbf{C D}$ system, the concentration of $\mathbf{Q}$ was $1 \times$ $10^{-5} \mathrm{~mol} \mathrm{~L}^{-1}$ and the concentration of $\mathbf{C D}$ varied according to experimental requirements.

\subsection{Optimizing experimental conditions}

For all measurements, the fluorescence emission intensities of Q-CD system were measured in $\mathrm{CH}_{3} \mathrm{OH}-\mathrm{PBS}(1: 99, \mathrm{v} / \mathrm{v}, \mathrm{pH}=$ 7.40) buffer solution and the excitation wavelength was $390 \mathrm{~nm}$. To obtain stronger fluorescence emission intensity of Q-CD system, the ratio of $\mathbf{C D}$ to $\mathbf{Q}$ was studied. In the same concentration of $\mathbf{Q}$, the fluorescence emission intensities of $\mathbf{Q}$ with different concentration of $\mathbf{C D}$ were recorded. The best ratio of $\mathbf{C D}$ to $\mathbf{Q}$ was selected according to the fluorescence emission intensity.

\subsection{Procedures for detection of copper ions}

To study the selectivity of Q-CD system on different metal ions $\left(\mathrm{Li}^{+}, \mathrm{Na}^{+}, \mathrm{K}^{+}, \mathrm{Mg}^{2+}, \mathrm{Ca}^{2+}, \mathrm{Cr}^{3+}, \mathrm{Mn}^{2+}, \mathrm{Fe}^{2+}, \mathrm{Fe}^{3+}, \mathrm{Co}^{2+}, \mathrm{Ni}^{2+}, \mathrm{Cu}^{2+}\right.$, $\left.\mathrm{Zn}^{2+}, \mathrm{Pb}^{2+}, \mathrm{Cd}^{2+}, \mathrm{La}^{3+}, \mathrm{Ce}^{3+}, \mathrm{Nd}^{3+}, \mathrm{Eu}^{3+}, \mathrm{Gd}^{3+}, \mathrm{Dy}^{3+}\right)$, each metal ions was added into Q-CD system, respectively. In the last 
solutions, $\left[\mathrm{Cu}^{2+}\right]=1 \times 10^{-5} \mathrm{~mol} \mathrm{~L}{ }^{-1}$, the concentration of other transition metal ions and rare earth ions was $2 \times 10^{-5} \mathrm{~mol} \mathrm{~L}^{-1}$, and the concentration of alkali metal ions and alkali earth metal ions was $5 \times 10^{-5} \mathrm{~mol} \mathrm{~L}^{-1}$. The fluorescence emission intensities of Q-CD system before and after adding metal ions were recorded.

To study the influence of the other metal ions on the recognition of Q-CD system to $\mathrm{Cu}^{2+}$, appropriate $\mathrm{Cu}^{2+}$ was added into Q-CD system to form Q-CD-Cu(II) system, then each of the other metal ions was added into Q-CD-Cu(II) system, respectively. In the last solutions, $\left[\mathrm{Cu}^{2+}\right]=1 \times 10^{-5} \mathrm{~mol} \mathrm{~L}^{-1}$, the concentration of other transition metal ions and rare earth ions was $2 \times 10^{-5} \mathrm{~mol} \mathrm{~L}^{-1}$, and the concentration of alkali metal ions and alkali earth metal ions was $5 \times 10^{-5} \mathrm{~mol} \mathrm{~L}^{-1}$. The fluorescence emission intensities of Q-CD-Cu(II) system before and after adding the other metal ions were recorded.

To obtain the relationship between the fluorescence emission intensity and the concentration of $\mathrm{Cu}^{2+}$, the fluorescence titration experiments were carried out. The fluorescence emission intensities of Q-CD system with various concentration of $\mathrm{Cu}^{2+}$ were recorded.

\subsection{Stoichiometric ratio}

The stoichiometric ratio between the $\mathbf{Q}$ and $\mathrm{Cu}^{2+}$ in $\mathbf{Q}-\mathbf{C D}-\mathbf{C u}(\mathrm{II})$ system was determined by Job's method. ${ }^{36}$

\subsection{Detecting $\mathrm{Cu}^{2+}$ in real samples}

To check the application of Q-CD system, we designed experiments to detect $\mathrm{Cu}^{2+}$ in water bodies, vegetables and fruits samples by Q-CD system probe. Water samples were collected from suburban and urban areas in Lianyungang and Huaian. Water samples were filtrated through a $0.22 \mu \mathrm{m}$-pore-size membrane. Nitric acid digestion was performed before metal analysis by ICP-AES and fluorescent sensor with this method. To accomplish this, each sample $(300 \mathrm{~mL})$ was evaporate to dryness, then $\mathrm{HNO}_{3}$ solution $(3 \%, 300 \mathrm{~mL})$ were added to digest at room temperature for $24 \mathrm{~h}$. Following filtration through a $0.22 \mu \mathrm{m}$-pore-size membrane, the concentrations of $\mathrm{Cu}^{2+}$ were determined by ICP-AES and fluorescent sensor with this method, respectively. Potato, tomato, watermelon and apple were purchased from supermarket and treated according to literature with some modification. ${ }^{37}$ The vegetables and fruits were homogenized and dried at $150^{\circ} \mathrm{C}$. The dried samples were digested by adding aqua regia and heated until they were colorless. Then, the samples were digested by adding perchloric acid, sulphuric acid and nitric acid and heated in reaction stills for about $12 \mathrm{~h}$ until a clear solution was obtained. The digested samples were evaporated to dryness, then $3 \% \mathrm{HNO}_{3}$ solution were added. Following filtration through a $0.22 \mu \mathrm{m}$-pore-size membrane, the concentrations of $\mathrm{Cu}^{2+}$ were determined by AAS and fluorescent sensor with this method, respectively.

\section{Conclusions}

CD could enhance the fluorescence intensity of $\mathbf{Q}$ obviously, and the stability of fluorescence intensity became better, which ensured Q-CD system had better selectivity on $\mathrm{Cu}^{2+}$, and the detection limit was lower and the linear range was larger. The detection mechanism was based on the formation of the Q-CDCu(II) complex, which induced the ICT effect. Moreover, the method was successfully applied to detect $\mathrm{Cu}^{2+}$ in water bodies, vegetables and fruits with stable recovery rate. In summary, QCD system could act as a fluorescent probe for detecting $\mathrm{Cu}^{2+}$ in aqueous media with high selectivity and sensitivity.

\section{Conflicts of interest}

There are no conflicts to declare.

\section{Acknowledgements}

This work was supported by Innovation Fund for Young Scholars of Nanjing Forestry University (CX2017004), the Natural Science Foundation of Jiangsu Province (Grants No. BK20151513), State Key Laboratory for Chemistry and Molecular Engineering of Medicinal Resources (Guangxi Normal University) (CMEMR2017-B06), and the Priority Academic Program Development of Jiangsu Higher Education Institutions.

\section{Notes and references}

1 G. J. Park, G. R. You, Y. W. Choi and C. Kim, Sens. Actuators, $B, 2016,229,257$.

2 S. Q. Liao, J. J. Zhao, Y. F. Qin and S. L. Zhao, RSC Adv., 2017, 88, 55668.

3 E. Gaggelli, H. Kozlowski, D. Valensin and G. Valensin, Chem. Rev., 2006, 106, 1995.

4 S. R. Zhang, Q. Wang, G. H. Tian and H. G. Ge, Mater. Lett., 2014, 115, 233.

5 A. M. Hernández-Martínez, C. Padrón-Sanz, M. E. TorresPadrón, Z. Sosa-Ferrera and J. J. Santana-Rodríguez, Anal. Methods, 2016, 8, 7141.

6 S. Lauwens, M. Costas-Rodríguez and F. Vanhaecke, Anal. Chim. Acta, 2018, 1025, 69.

7 D. Alexander, R. Ellerby, A. Hernandez, F. C. Wu and D. Amarasiriwardena, Microchem. J., 2017, 135, 129.

8 F. Divsa, N. Isapour, H. Kefayati, A. Badiei, A. Nezhadali, S. Easapour and M. Yadavi, J. Porous Mater., 2015, 22, 1655.

9 Y. L. Gao, C. Zhang, S. W. Peng and H. Y. Chen, Sens. Actuators, B, 2017, 238, 455.

10 S. Q. Liao, J. J. Zhao, Y. F. Qin and S. L. Zhao, $R S C A d v ., 2017$, 7, 55668.

11 X. Wang, T. Qin, S. S. Bao, Y. C. Zhang, X. Shen, L. M. Zheng and D. R. Zhu, J. Mater. Chem. A, 2016, 4, 16484.

12 X. L. Zhang, X. H. Guo, H. H. Yuan, X. Jia and B. Dai, Dyes Pigm., 2018, 155, 100.

13 S. B. Warrier and P. S. Kharkar, J. Lumin., 2018, 199, 407.

14 J. Wang, R. S. Li, H. Z. Zhang, N. Wang, Z. Zhang and C. Z. Huang, Biosens. Bioelectron., 2017, 97, 157.

15 C. Li, X. T. Han, S. S. Mao, S. O. Aderinto, X. K. Shi, K. S. Shen and H. L. Wu, Color. Technol., 2018, 134, 230. 
16 S. L. Yang, B. Yin, L. Xu, B. H. Gao, H. J. Sun, L. T. Du, Y. Tang, W. N. Jiang and F. L. Cao, Anal. Methods, 2015, 7, 4546.

17 S. D. S. Parveen, B. S. Kumar, S. R. Kumar, R. I. Khan and K. Pitchumani, Sens. Actuators, B, 2015, 221, 75.

18 S. L. Yang, W. N. Jiang, F. Y. Zhao, L. Xu, Y. Y. Xu, B. H. Gao, H. J. Sun, L. T. Du, Y. Tang and F. L. Cao, Sens. Actuators, B, 2016, 236, 386.

19 Y. Liu, X. Wu, H. P. Zhou, X. Y. Liu, F. J. Zhang and J. H. Yang, Luminescence, 2009, 24, 416.

20 P. Liu, L. L. Zhao, X. Wu, F. Huang, M. Q. Wang and X. D. Liu, Spectrochim. Acta, Part A, 2014, 122, 238.

21 S. Uzasc and F. B. Erim, J. Chromatogr. A, 2014, 1338, 184.

22 S. S. M. Rodrigues, D. S. M. Ribeiro, L. Molina-Garcia, A. R. Medina, J. A. V. Prior and J. L. M. Santos, Talanta, 2014, 122, 157.

23 M. Hosseini, H. Khabbaz, A. S. Dezfoli, M. R. Ganjali and M. Dadmehr, Spectrochim. Acta, Part A, 2015, 136, 1962.

24 X. J. Zhao, H. J. Wang, L. J. Liang and Y. F. Li, Spectrochim. Acta, Part A, 2013, 103, 68.

25 X. H. Liu, W. H. Ding, Y. S. Wu, C. H. Zeng, Z. X. Luo and H. B. Fu, Nanoscale, 2017, 9, 3986-3994.

26 S. B. Bukhari, S. Memon, M. Mahroof-Tahir and M. I. Bhanger, Spectrochim. Acta, Part A, 2009, 71, 1901.
27 C. L. Yan, X. H. Li, Z. L. Xiu and C. Hao, J. Mol. Struct.: THEOCHEM, 2006, 764, 95.

28 I. M. Savic, V. D. Nikolic, I. Savic-Gajic, L. B. Nikolic, B. C. Radovanovic and J. D. Mladenovic, J. Inclusion Phenom. Macrocyclic Chem., 2015, 82, 383.

29 T. F. Kellici, D. Ntountaniotis, G. Leonis, M. Chatziathanasiadou, A. V. Chatzikonstantinou, J. Becker-Baldus, C. Glaubitz, A. G. Tzakos, K. Viras, P. Chatzigeorgiou, S. Tzimas, E. Kefala, G. Valsami, H. Archontaki, M. G. Papadopoulos and T. Mavromoustakos, Mol. Pharmaceutics, 2015, 12, 954.

30 M. Zhang, Y. H. Zhang and L. Ma, Chin. J. Anal. Chem., 2011, 39, 1907.

31 L. Q. Gu, X. J. Wan, H. Y. Liu, T. Q. Liu and Y. W. Yao, Anal. Methods, 2014, 6, 8460.

32 A. L. Zhou and O. A. Sadik, J. Agric. Food Chem., 2008, 56, 12081.

33 G. Le Nest, O. Caille, M. Woudstra, S. Roche, F. Guerlesquin and D. Lexa, Inorg. Chim. Acta, 2004, 357, 775.

34 J. P. Cornard and J. C. Merlin, J. Inorg. Biochem., 2002, 92, 19.

35 F. C. Yu, S. M. Lai and S. Y. Suen, Sep. Sci. Technol., 2003, 38, 1033.

36 A. Facchiano and R. Ragone, Anal. Biochem., 2003, 313, 170.

37 H. K. Das, A. K. Mitra, P. K. Sengupta, A. Hossain, F. Islam and G. H. Rabbani, Environ. Int., 2004, 30, 383. 